\title{
TECNOLOGIAS DIGITAIS DE INFORMAÇÃO E COMUNICAÇÃO E O ENSINO DE MATEMÁTICA PARA PESSOAS COM PARALISIA CEREBRAL
}

Denner Dias Barros ${ }^{1}$, Danielle Aparecida do Nascimento Santos ${ }^{2}$, Ana Mayra Samuel Silva ${ }^{3}$, Janiele de Souza Santos ${ }^{1}$, Elisa Tomoe Moriya Schlünzen ${ }^{4}$

${ }^{1}$ Discente do curso de Matemática na Universidade Estadual Paulista - UNESP - Presidente Prudente/SP. ${ }^{2}$ - Mestre em Educação pela Universidade Estadual Paulista - UNESP - Presidente Prudente/SP. ${ }^{3}$ Discente do curso de Pedagogia na Universidade Estadual Paulista - UNESP - Presidente Prudente/SP. ${ }^{4}$ Docente da Universidade Estadual Paulista UNESP - Presidente Prudente. . E-mail: denner_dbarros@yahoo.com.br. Agência Financiadora: CAPES/OBEDUC

\section{RESUMO}

Inserir as Tecnologias Digitais de Informação e Comunicação (TDIC) na educação é um processo que possibilita condições igualitárias de aprendizado, principalmente dos estudantes que possuem alguma forma de limitação motora ou cognitiva. O presente artigo visa apresentar o trabalho realizado nos acompanhamentos semanais de estudantes com Paralisia Cerebral de forma que por meio de um plano de aulas previamente elaborado, de forma flexível e associada à utilização das TDIC e uso de projetos possa possibilitar ao estudante, dentro de suas próprias limitações, o desenvolvimento de suas habilidades no estudo da matemática de forma que seja oferecido um suporte utilizando diferentes recursos pedagógicos e tecnológicos e tornando possível a inclusão digital, social e escolar dessas pessoas.

Palavras-chave: Uso de Tecnologias Digitais de Informação e Comunicação, Paralisia Cerebral, Ensino da Matemática, Estudantes Público Alvo da Educação Especial, Atendimento Educacional Especializado.

\section{INTRODUÇÃO E OBJETIVO}

O desenvolvimento e a utilização de recursos digitais para a Educação, como softwares educativos e demais Tecnologias Digitais de Informação e Comunicação (TDIC) que são aplicados no processo de ensino e aprendizagem dos Estudantes Público-Alvo da Educação Especial (EPAEE), podem ser entendidos como uma forma de potencializar as habilidades de cada estudante, explorando-as de maneira única. Pesquisas na área da Educação Especial e Inclusiva têm ampliado os métodos de abordagem das TDIC no ensino para os EPAEE, tornando cada vez mais significativa a exploração destes recursos. Segundo Schlünzen (2000) o desenvolvimento de projetos pode permitir que as informações vividas tornem-se significativas para os alunos e possam ser transformadas em conhecimento, favorecendo a formalização de cada conceito.

A inclusão dos EPAEE, nos contextos escolar, digital e social é um direito de todos. De acordo com o BRASIL (2010), a inclusão educacional é um direito do aluno e requer mudanças na concepção e nas práticas de gestão, de sala de aula e de formação de professores, para a efetivação do direito de todos à escolarização. 
Os EPAEE sejam com deficiências físicas, sensoriais e múltiplas; transtornos globais do desenvolvimento e altas habilidades/superdotação, quando incluídos na escola pública são direcionadas para um estudo complementar, denominado Atendimento Educacional Especializado (AEE) que deve ser realizado no contraturno do ensino regular. Esse atendimento é realizado nas Salas de Recursos Multifuncionais (SRM), destinadas ao AEE dentro da escola comum, complementando ou suplementando o ensino formal por um professor especialista, que deve ter domínio especializado em: Língua Brasileira de Sinais, Língua Portuguesa na modalidade escrita como segunda língua, sistema Braille, Soroban, orientação e mobilidade, atividades de vida autônoma, desenvolvimento dos processos mentais superiores, programas de enriquecimento curricular, adequação e produção de materiais didáticos e pedagógicos, utilização de recursos ópticos e não ópticos, Tecnologia Assistiva e outros.

Nesta perspectiva, as pessoas com Paralisia Cerebral (PC) podem ser beneficiadas na ampliação e estímulo de suas habilidades, desde que sejam entendidos e estudados os seus próprios limites. A Associação Brasileira de Paralisia Cerebral $(2009$, p. 1) define PC como um grupo de perturbação do desenvolvimento do movimento e da postura, causando limitações nas atividades. Acrescenta que são atribuídas a distúrbios não progressivos que ocorrem no cérebro em desenvolvimento. As desordens motoras da Paralisia Cerebral são comumente seguidas por alterações na sensação, percepção, cognição, comunicação e comportamento, podendo também ser acompanhadas por crises convulsivas.

Segundo (SOUZA, 1998), PC pode ser classificada como, Espástica (Movimentos duros e difíceis), Extrapiramidal (Movimentos involuntários ou descontrolados) e Atáxica (Coordenação e equilíbrio ruins). A autora relata que dependendo da localização do corpo que foi afetada, os tipos mencionados apresentam subdivisões: Tetraparesia (os quatro membros estão igualmente comprometidos), Diparesia (quando os membros superiores apresentam melhor função do que os membros inferiores) e Hemiparesia (quando somente um lado do corpo é afetado).

No trabalho desenvolvido com os estudantes, realizamos as atividades com o aluno $\mathrm{T}^{1}$, que possui Paralisia Cerebral do tipo espástica. De acordo com o BRASIL (2006), neste caso, o maior dano se dá no córtex motor. Os músculos são facilmente irritáveis e contraem-se a partir da menor estimulação. A criança espástica apresenta rigidez muscular, ou tensão muscular. Isto significa dizer que os movimentos são rígidos, lentos e desajeitados. Esta rigidez tende a aumentar quando a criança vai emitir um comportamento voluntário, quando está aborrecida ou excitada,

\footnotetext{
${ }^{1}$ Utilizamos a inicial do nome do estudante a fim de preservar sua identidade.
} 
ou ainda, quando o seu corpo está em determinadas posições. O padrão de rigidez varia muito de criança para criança, mas o primeiro passo para facilitar que esta criança manipule e explore os objetos é a mesma estar bem posicionada.

Os atendimentos com o estudante foram realizados nos âmbitos do Centro Promoção para Inclusão, Digital e Social (CPIDES), da Universidade Estadual Paulista Júlio de Mesquita Filho (UNESP), campus de Presidente Prudente/SP. Este centro é um ambiente onde se realizam atendimentos utilizando recursos pedagógicos, voltados para os EPAEE, buscando sua inclusão. Este trabalho beneficia pro volta de 30 estudantes e é realizado por cerca de 14 pesquisadores e 40 estudantes dos cursos de graduação da UNESP. Os atendimentos são realizados na Sala de Recursos Multifuncionais (SRM) e no laboratório de informática.

$\mathrm{O}$ aluno $\mathrm{T}$, possui atualmente 15 anos de idade, frequenta o primeiro ano do ensino médio regular e participa das atividades do CPIDES semanalmente, sendo uma hora por atendimento, uma vez por semana. Mostra-se sempre disposto para realizar as atividades propostas, característica que facilita os atendimentos de maneira geral. É importante relatar que a interação entre estagiário e aluno é positiva, tornando o atendimento mais dinâmico.

O objetivo principal desta pesquisa é propor e aplicar com base na metodologia do trabalho com projetos, atividades diversificadas do ensino da matemática na SRM para estudantes com PC.

\section{METODOLOGIA}

Esta pesquisa foi realizada mediante o projeto que encontra-se cadastrado no Comitê de Ética em Pesquisa (CEP) sobre protocolo 106/2009.

$\mathrm{Na}$ primeira etapa da pesquisa, que se configura como qualitativa, foi realizada uma entrevista estruturada junto aos responsáveis pelo estudante para levantamento de informações norteadoras que possibilitam diagnosticar os objetivos, dificuldades, potencialidades e interesses dos estudantes. Diante das informações obtidas, é possível elaborar um plano de aulas com base nas TDIC que inicialmente apresentavam-se como mais propícias para as atividades propostas, tendo em vista o perfil de cada estudante atendido. A partir dos dados coletados na entrevista com os responsáveis, foi possível diagnosticar as dificuldades do estudante com relação aos conceitos matemáticos básicos e na interpretação e contextualização de problemas e isso permitiu um melhor direcionamento das atividades desenvolvidas, a fim de permitir que o estudante realmente aprenda. 
Antes de dar início a intervenção, realizamos um levantamento bibliográfico sobre as principais características da pessoa com PC e do ensino de matemática para estes estudantes, em artigos científicos e sites especializados no assunto, como por exemplo o site da Associação Brasileira de Paralisia Cerebral. Levantamos também materiais relacionados às disciplinas que foram vistas de forma defasada no estudante, como as operações básicas matemáticas, frações e relações monetárias, além da escolha das TDIC. Em seguida, realizamos uma análise criteriosa da literatura selecionada. A partir das informações levantadas, elaboramos planos de aulas baseados no trabalho com projetos, onde foram propostas atividades de uso das TDIC para que a aprendizagem do estudante fosse potencializada.

Em um primeiro contato com o aluno $\mathrm{T}$, fizemos uma avaliação diagnóstica para comprovar as dificuldades, que foram significativas na análise de grandezas e na manipulação de símbolos nas operações em geral e também o aluno não conseguia realizar as operações de multiplicação e divisão. Vale ressaltar também que conseguimos detectar as potencialidades do estudante, a saber: em conseguir resolver de maneira simples exercícios de raciocínio lógico. Levantamos também seus assuntos de interesse, onde podemos citar temas como futebol, basquete e internet.

Utilizamos como base os Objetos de Aprendizagem (OA), como "Fazenda Rived", software que trabalha questões como relações biunívocas, sequências lógicas e contagem, "Um Dia de Compras" e "Festa de Aniversário", que possuem atividades que envolvem relações monetárias e de raciocínio lógico, estes entre outros $\mathrm{OA}$, que podem ser encontrados no Banco Internacional de Objetos Educacionais (BIOE). Estes recursos tecnológicos educacionais foram utilizados sempre aliados à atividades práticas, como a de compra e venda na forma de simulação para trabalhar as relações monetárias e o conhecimento de dinheiro e atividades de leitura e interpretação de textos com assuntos de interesse do estudante, para a elaboração de problemas matemáticos envolvendo estes temas.

No decorrer do processo, analisamos o desenvolvimento do aluno T sempre de maneira criteriosa, através de situações lúdicas para permitir que o estudante se expressasse de maneira livre e para que a avaliação fosse contínua.

\section{RESULTADOS}

O uso das TDIC como estratégia pedagógica permitiu ao estudante o desenvolvimento de competências, habilidades cognitivas, afetivas e sociais, tais como a resolução de operações 
matemáticas, reconhecimento de valores de dinheiro e a realização de compras, dando-lhe condições de ser incluído socialmente e também no mundo digital.

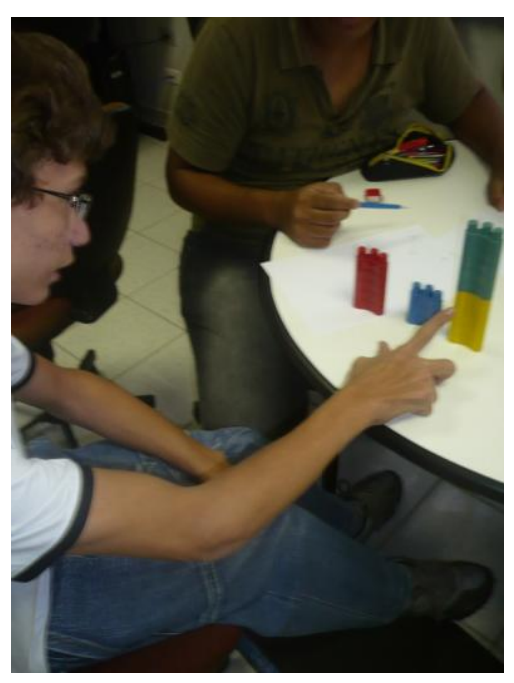

Figura 1. Foto do Aluno T realizando o teste diagnóstico.

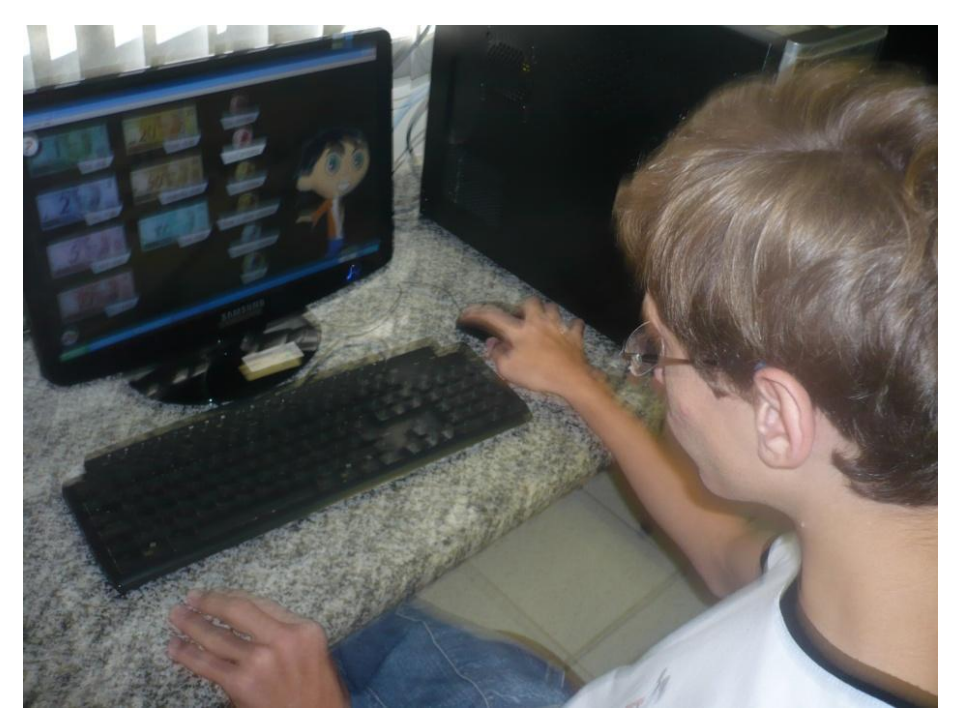

Figura 2. Foto do aluno T realizando atividades no objeto educacional "Festa de Aniversário". 


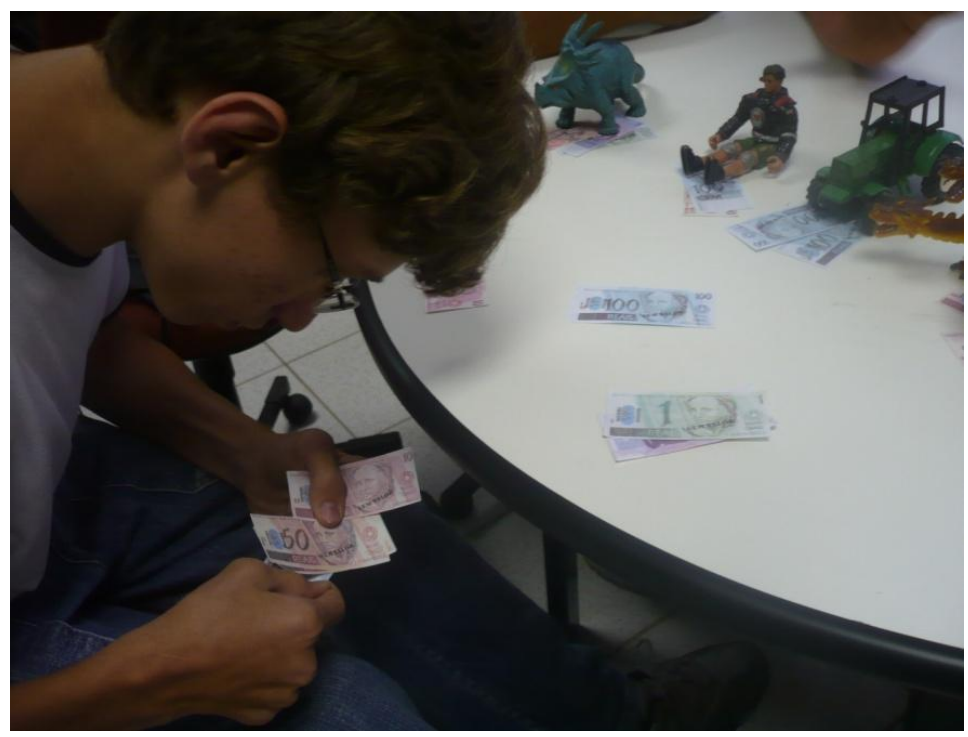

Figura 3. Foto do aluno realizando atividade de compra e venda na SRM.

Os avanços obtidos pelo estudante foram positivos, e foi possível reconhecer que as atividades desenvolvidas foram produtivas devido ao fato de estarem sempre centradas nos seus interesses e necessidades, possibilitando uma aprendizagem significativa. $\mathrm{O}$ uso de projetos foi essencial uma vez que permite respeitar diferentes temas, de diversas maneiras e estratégias.

"O professor que trabalha com projetos de aprendizagem respeita os diferentes estilos e ritmos de trabalho dos alunos desde a etapa de planejamento, escolha do tema e respectiva problemática a ser investigada. Não é o professor quem planeja para os alunos executarem, ambos são parceiros e sujeitos de aprendizagem, cada um atuando segundo o seu papel e nível de desenvolvimento" (ALMEIDA, 1999, p. 2).

Por conseguinte, consideramos que o processo de ensino e aprendizagem mediado pelos estagiários obteve avanços significativos. Esses mediadores tiveram um papel fundamental em despertar a curiosidade e interesse do estudante, possibilitando a realização de atividades contextualizadas e a construção do conhecimento básico de valores em áreas específicas da matemática como álgebra, geometria e principalmente na aritmética. 


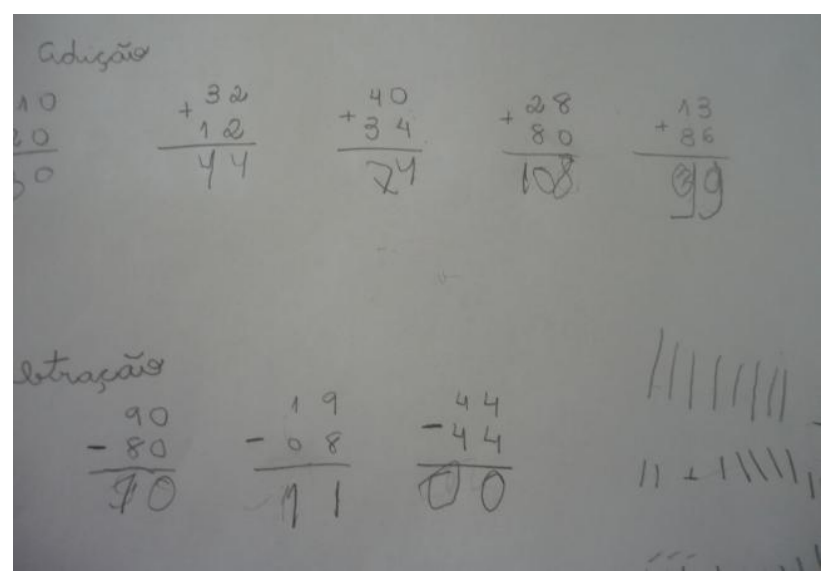

Figura 4. Foto de atividade com operações matemáticas do aluno.

Neste sentido, o trabalho realizado trouxe a possibilidade de amenizar as dificuldades de aprendizagem encontradas inicialmente no estudante. Assim, com o alcance dos resultados positivos no processo de aprendizagem de matemática, o estudante se sentiu mais seguro, autônomo e capaz de realizar atividades cotidianas, como compras e operações básicas, bem como em atividades desenvolvidas na escola.

\section{DISCUSSÃO}

Todas as atividades foram propostas e desenvolvidas com o objetivo de atingir o patamar de um ambiente Construcionista, Contextualizado e Significativo (CCS), que segundo Schlünzen (2000, p. 82),

É um ambiente favorável que desperta o interesse do aluno e o motiva a explorar, a pesquisar, a descrever, a refletir, a depurar as suas ideias. [...] As informações que são significativas para o aluno podem ser transformadas em conhecimento [...] O aluno consegue descobrir a relação com tudo que está aprendendo, a partir de seus interesses individuais dentro do seu contexto.

Nesta perspectiva, tornando este aprendizado da matemática significativo para o EPAEE, a partir dos seus interesses podemos provocar no estudante maior interesse em aprender matemática e, por conseguinte, um estímulo maior para que ele possa se desenvolver cada vez mais, tendo os estudos como algo prazeroso, divertido e necessário.

\section{CONCLUSÃO}

A pesquisa realizada possibilitou reconhecer estratégias para amenizar as dificuldades de aprendizagem do estudante, bem como explorar e potencializar seu aprendizado de forma 
significativa. Assim, com o alcance dos resultados positivos no processo de aprendizagem mediado pelo uso de TDIC, o estudante torna-se autônomo para desenvolver atividades que antes não conseguiam, por serem totalmente dependentes. Vale ressaltar que o uso das TDIC em um ambiente construcionista, contextualizado e significativo possibilitou uma aprendizagem de todos os EPAEE atendidos, ainda que esta tenha ocorrido de forma diferente em tempos distintos.

\section{REFERÊNCIAS}

ABPC - Associação Brasileira de Paralisia Cerebral. Disponível em:< http://www.paralisiacerebral.org.br/saibamais06.php >. Acesso em: 25 de setembro de 2012.

ALMEIDA, M. E. Projeto: uma nova cultura de aprendizagem. São Paulo: PUC/SP, 1999.

BIOE - Banco Internacional de Objetos Educacionais. Disponível em: < http://www.objetoseducacionais2.mec.gov.br/<. Acesso em: 25 de setembro de 2012.

BRASIL: Ministério da Educação. Secretaria de Educação Especial. Saberes e práticas da Inclusão: Desenvolvendo competências para o atendimento às necessidades educacionais de alunos com deficiências física/neuro-motora. Brasília: MEC/SEESP, 2006.

BRASIL: Ministério da Educação. Secretaria da Educação Especial. Manual de Orientação: Programa de Implementação de Sala de Recursos Multifuncionais. Brasília: MEC/SEESP, 2010.

SCHLÜNZEN, E. T. M. Mudanças nas práticas pedagógicas do professor: criando um ambiente construcionista, contextualizado e significativo para crianças com necessidades especiais físicas. 2000, 240 f. Tese (Doutorado em Educação: Currículo), Pontifícia Universidade Católica de São Paulo, São Paulo, 2000.

SOUZA, A. M. C; FERRARETTO, I. Paralisia Cerebral: aspectos práticos. São Paulo, SP: Memnon, 1998. 